\title{
PBIS: Towards a Kinder Form of Discipline
}

\section{Pollyanna Stalie}

Positive Behavioral Interventions and Supports (PBIS) is a practical theory of discipline that focuses on prevention-rather than punishment,-and affirmation of preferred behavior. PBIS is primarily used in schools, and I have used it extensively in my work as an early childhood educator. In this paper, I argue that there is a clear connection between the psychological theory that makes PBIS effective and the sociopolitical philosophies laid out by John Dewey, Friedrich Nietzsche, and Michel Foucault. These theories and methodologies explain power dynamics between a dominant and non-dominant group, and how best to discipline to correct behavior long-term while instilling a sense of agency in the subjugated group. I ultimately conclude that PBIS works to improve classroom function through the implementation of mutual respect and by validating children's needs by giving them a sense of agency. Integrating PBIS in societal institutions can serve as the basis for a new kind of discipline that would, I contend, improve these institutions in myriad way.

\section{Background}

Like many philosophy undergraduates, my philosophical interests have been shaped by my prior experience. These interests tend to be practical in nature; they pertain to things in my day-today life, such as my work as an early childhood educator. My mother has owned a child development center for 15 years, and I have worked there for five. In addition, I have volunteered and was eventually hired at a non-profit that provides parenting classes. Working with children in both cases has taught me a tremendous amount about child development and early childhood education. These experiences have radically shifted my perception of the world at large. Through my work, I have become fascinated with questions about the movement of power dynamics in a classroom setting, how these dynamics affect children's sense of self, and how to run a functional classroom.

\section{Introduction}

These questions all seem to be answered by Positive Behavioral Interventions and Supports (PBIS), which is a behavior management tool used in early childhood education. As I learned more about PBIS through training, watching it being used by my co-teachers, and implementing it myself, I came to realize how effective it is for the children and for my peace of mind working with them. Digging into how PBIS was developed, I discovered that there were connections between the psychological theory that makes PBIS work and the philosophical theories laid out by Friedrich Nietzsche, Michel Foucault and John Dewey, I intend to explore the specific ways in which each 
theory and methodology articulate how best to encourage the function of institutions that involve power dynamics. These theories and methodologies explain power dynamics between a dominant and non-dominant group, and how best to discipline to correct behavior long-term, while instilling a sense of agency in the subjugated group. I will ultimately explain that PBIS works to improve classroom function through the implementation of mutual respect, and by validating children's needs through granting them a sense of agency. From this explanation I will derive the conclusion that integrating PBIS in societal institutions can serve as the basis for a new kind of discipline that would improve the function of said institutions. This piece works to inspire a moderate shift in how we utilize the structures we have in place and aims itself at the creation of a form of discipline that acknowledges that it is speaking to fellow humans with agency, autonomy, and will.

\section{On PBIS}

PBIS is a tool kit of methods based on a foundation of behavioral research. PBIS (also called PBS) asserts that the prevention of negative behaviors through reinforcement and affirmation of positive behaviors is an effective way to maintain a functioning classroom. According to the Edward G. Carr and his fellow researchers, "PBS is an applied science that uses educational methods to expand an individual's behavior repertoire."1 PBIS works because if children know what to do and are rewarded for doing the right thing, they will be more inclined to follow that pattern of behavior; whereas punishment will discourage one type of action, and disregards why the child is behaving that way. For example, if a teacher wants a hyperactive child to stop running by punishing the child every time she runs, she will learn to skip instead. Punishing the child did not change the fact that she is a hyperactive child. Punishment does not work to alter a child's behavior long-term, and this is where operant conditioning comes into play.

\section{On Operant Conditioning}

The psychological aspects of PBIS will be addressed in brief, in an attempt to keep my analysis philosophical. That being said, it is necessary to understand operant conditioning to understand how PBIS works. Operant behavior is essentially the idea that a behavior is an external communication of an internal thought, i.e., the behavior that we are in control of (or non-reflexive behavior) is purposeful. The researcher B.F. Skinner, who developed this idea, explains that "reinforcement is extraordinarily important. That is why it's reassuring to recall that its place was once taken by the concept of purpose; no one is likely to object to a search for purpose in every

1. Edward G. Carr et al., "Positive Behavior Support," Journal of Positive Behavior Interventions 4, no.1 (2002): 4, https://doi.org/10.1177/109830070200400102. 
human act."2 Since conscious behaviors have a purpose, they can be encouraged and discouraged through positive and negative reinforcement and affirmation. This means that, in theory, if a subject receives a reward every time they perform an action, they will perform that action more often. Conversely, if the subject is punished after they perform an action, they will do that action less often or stop doing it entirely. Skinner's work on operant behavior ultimately concludes that purposeful human behavior can be manipulated by external stimuli. PBIS acknowledges operant behavior and heavily subscribes to the notion that humans have the agency to behave in a way that communicates their will (they act towards the purpose of an end). If operant conditioning is ineffective, redirection is used to diffuse a non-preferred action.

\section{On Redirection}

PBIS focuses on redirection as a method for discouraging behavior in order to avoid punishment entirely. Redirection, or replacement skills, attempts to address the child's impulse to behave a certain way and direct their action towards a preferred behavior. This approach and its outcomes are explained as follows by the Center on PBIS: "PBIS practices are preventative and responsive ... When implemented with fidelity, classroom PBIS practices lead to fewer disruptions, improved student behavioral and academic outcomes, and more time spent teaching."3 PBIS utilizes a variety of strategies to achieve its goals, including but not limited to using redirection and correction to respond to problem behavior, acknowledging expected behavior with praise, and actively prompting and supervising students. ${ }^{4}$ Children's behavior is a response to their environment; it is a combination of nature and nurture. Using this holistic approach, PBIS attempts to understand the root cause of a specific behavior. For example, if a child is chronically throwing sand, instead of removing the child from the sand, the teacher would always give the child a ball after saying something like "you cannot throw the sand, but you can throw the ball." Thus, when the child listens and throws the ball instead, the teacher would praise the child for listening by saying "nice job listening to my words." Redirection and clear expectations encourage preferred behavior, and positive affirmation after the child listens reinforces this preferred behavior. These methods are used in PBIS to alter a child's behavior for the better in a way that does not feel abrasive to both the child and the teacher; non-preferred behaviors are teaching moments. Redirection and operant conditioning both work to support the overall goal of PBIS.

2. B.F. Skinner, "Operant Behavior," American Psychologist 18, no. 8 (1963): 515, https://doi.org/10.1037/ h0045185.

3. "Classroom PBIS," Center on PBIS, accessed February 16, 2020, https://www.pbis.org/topics/ classroom-pbis.

4. "Classroom PBIS," Center on PBIS. 
On the Goal of PBIS

The goal of PBIS is to change the course of behavior in a child's life, by carefully reviewing what motivates non-preferred behaviors. The point of PBIS is not simply to manage a classroom, but to try to get the child to be able to question themselves before acting. As Carr et al. explain, "The primary goal of PBS is to help an individual change his or her lifestyle in a direction that gives all relevant stakeholders (e.g., teachers, employers, parents, friends, and the target person him- or herself) the opportunity to perceive and to enjoy an improved quality of life." 5 This "improved quality of life" can also be explained as fostering a sense of morality or critical thinking skills in a child's mind. If caregivers explain exactly why the child cannot do something, they work to validate the need that motivates the child's behavior; by giving the child options, they will most often walk away feeling empowered to make better decisions next time. PBIS is an educational tool that rejects punishment and works to validate children's needs by giving them choices, while still guiding behavior. The teacher is a guiding figure that fosters a sense of agency and empowerment in her students; avoiding the need for punishment entirely. The main objective of PBIS can be extended to Friedrich Nietzsche's argumentative framework in his work, On the Genealogy of Morality.

\section{Nietzsche}

\section{On the Creditor-Debtor Relationship}

In Nietzsche's On the Genealogy of Morality, he critiques the punitive aspects of the justice system. The punitive aspects of the justice system are explained in part by what he calls the "creditor and debtor relationship." Nietzsche asserts that the justice system is punitive, and because it is punitive, it creates suffering. In theory, suffering is supposed to be treated as a means to a higher end; those in power causing intentional pain to the accused as a consequence of the accused (supposed) action is intended to discourage that action in the future (for the accused and for society as a whole) and create a feeling of guilt in performing the same negative action in the future.

The supposed goal of this punishment is to instill a moral compass in the sufferer, or so that the accused can pay her debt to society. PBIS accounts for this in the way that punitive measures are not included in its methods, as they largely do not work towards achieving the supposed goals of the justice system. Nietzsche describes why punitive methods do not work through his description of the creditor/debtor relationship, writing, "This idea of an equivalence between injury and pain ... [originated] in the contractual relationship between creditor and debtor." 6 Throughout this analysis,

5. Carr et al., "Positive," 5.

6. Friedrich Nietzsche, On the Genealogy of Morality, ed. Keith Ansell-Pearson, trans. Carol Diethe, (Cambridge: Cambridge University Press, 2008), 40. 
the relationship between creditor and debtor has been evaluated, as it can be seen in the student/ teacher and justice system/accused relationships as described above.

The PBIS system understands that this is not a serviceable foundation for student/teacher relationships and asserts the need for prevention and clear boundary setting prior to a behavior occurring. The creditor and debtor relationship creates a platform for suffering in the power imbalance that it affirms; the creditor can decide to what extent the debtor will suffer, under the guise of natural reparations for the debtor's misbehavior, when the reality is that only the creditor stands to benefit.

\section{On PBIS and the Creditor/Debtor Relationship}

PBIS and Nietzsche both recognize that punishment serves creditors (or people who have the power in a relationship), and it does not help develop a sense of morality in the debtor. PBIS focuses on redirection as a method for discouraging behavior in order to avoid punishment entirely. In PBIS, for example, if the child is throwing sand, instead of removing the child from the sand, the teacher would give the child a ball after saying something like, "You cannot throw the sand, but you can throw the ball."

The methods used in PBIS avoid the dissatisfaction that Nietzsche describes here: "On the whole, punishment makes men harder and colder ... it sharpens the feeling of alienation; it strengthens the power to resist ... we can safely conclude that the evolution of a feeling of guilt was most strongly impeded through punishment." 7 Nietzsche's claim that guilt is impeded through punishment applies to all humanity, children included. PBIS and Nietzsche agree that punishment does not establish a sense of morality. Punishment is not effective in the justice system because of the debtor and creditor power dynamic (or in PBIS, the student and authoritarian teacher dynamic). This does not mean that traditional forms of punishment and PBIS are mutually exclusive, but rather to place emphasis on the fact that in most cases energy can be redirected in safe, effective ways. The feelings that arise from this punishment are not constructive, and these feelings are described in Nietzsche's concept of ressentiment.

\section{On Punishment and Ressentiment}

The concept of ressentiment is first mentioned in Nietzsche's second essay and is related to the question: what is the value of justice? Nietzsche's perspective is that ressentiment, (also known as the slave morality), creates conditions wherein revenge is mistaken for justice. A more accurate statement would be that a harm committed against someone is a harm committed against the concept of justice; the crime in and of itself is not a personal offense. The justice system as a

\section{Nietzsche, Genealogy of Morality, 54.}


punitive body perpetuates harm in this way because a power dynamic is set up in which the more powerful entity, the prosecutor, has power over the subordinate entity, the defendant. Nietzsche explains how this tit-for-tat mentality can be harmful: “This 'scientific fairness' immediately halts and takes on aspects of a deadly animosity and prejudice the minute it has to deal with a different set of emotions." Ressentiment is the recasting of an injustice as a personal attack against one's sense of humanity, creating a bruised ego. This recasting is exclusively done by those who are already victims of an unfair power structure who then become prosecutors after an injustice is committed against them. Any injustice committed against these victims (who have become prosecutors) is tainted by strong, spiteful emotions. This is because if the victim's circumstances are cruel in and of themselves, any additional injustice is an unnecessary hardship, adding weight to an already sinking ship. These spiteful emotions make the prosecutor more creative in the punishing of the accused. Their pain stewing from the injustice after it has been committed, unleashes a kind of creative capacity, motivated by anger and hurt. The prosecutor seeks to "get even," which is not justice-but revenge.

For example, if a debtor is robbed, ressentiment will make them believe that the thief had spiteful intentions and make the debtor want to harm the thief, in an attempt to re-create the pain that the debtor felt post-act. The thief may have needed something and had no other means to achieve that goal, committing an injustice with no emotional motivation behind it. The justice system is an active application of ressentiment, because the prosecutor is given the power to punish the defendant, recasting the prior action taken by the defendant as a personal attack on the prosecutor. This is an attempt to give the prosecutor the opportunity to take back what they lost, even though that is only abstractly possible. It should be noted that this argument would only apply to crimes in which the motivation of the accused indirectly affects those who are harmed by the action; meaning that the accused that had caused harm to the victim did so inadvertently. Different moral considerations should be made if there was intentional physical harm made by the accused against the prosecutor or to society at large. While PBIS has its place in re-imagining our justice system, it is not a catch-all system. Justice is a complex theoretical issue and an analogy can be drawn connecting PBIS and Nietzsche, but these necessary moral considerations must come in to complicate the story.

Then, Nietzsche goes on to explain how the justice system is flawed because it tries to enact revenge for the injured party when this only accounts for the origin of justice and not the utility of justice. Extrapolating on this idea, Nietzsche writes, "A system of law conceived as sovereign and

8. Nietzsche, Genealogy of Morality, 48. 
general, not as a means for use in the fight between units of power but as a means against fighting in general." 9 Essentially, Nietzsche is arguing that justice is a human construct and without the imposition or enforcement of justice through a legal system, justice is only the origin of itself. Justice does not "do" anything good because it has no real utility when it is put into use to mediate a fight between two individual wills. Here, the value of justice is framed as a "means against fighting in general," which means that ideally there is benevolent care enacted when just decisions are made.

\section{On Punishment, Ressentiment, and PBIS}

Nietzsche and PBIS agree that if those who hold power seek to "get even" with those who have wronged them (or someone they are representing), the whole system is compromised. Justice is to be utilized as a force for good, meaning that mistakes are learned from in order to improve each individual, because at the collective level, individuals comprise society as a whole. We all must live and work together, and power dynamics are necessary because we are scattered but social creatures that need direction in one way or another. Those in power have the capability to teach those who do not have power if they so choose to, and that is what Nietzsche and PBIS call for.

PBIS largely agrees with Nietzsche's perception of justice, that an eye for an eye makes the whole world blind. Both PBIS and Nietzsche understand that one will against another can only result in frustration from both parties. It is extremely difficult if not nearly impossible to retroactively punish someone. Once a child has misbehaved, making them sit out only serves to make the child resentful of those in power. The child will not come back with a brilliant, intuitive way to change their behavior for the better. Unless the child is continuously educated as to why their will and therefore their agency is being impeded, the child will likely fester in spite of those in power. Agency in this context means having a will and having the power to make the choice of what action to take as a result of that will. Sending people of any age away does not teach them anything; it is an act that abandons their spirit, neglects their mind, and it surrenders their potential—against their will and therefore their agency.

PBIS and Nietzsche agree that punishment as a result of non-cooperation from the less powerful entity will not conjure up any sense of morality or guilt as a result of said punishment. PBIS accounts for this by applying the following methods: when conflict arises with a student, information about the conditions in which the student lives are used to understand the function that the problem behavior in question is serving. ${ }^{10}$ In this way, PBIS strives to understand what motivates the child's will to act, and to understand the root cause of a non-preferred action. Teachers are to

9. Nietzsche, Genealogy of Morality, 50.

10. "Tier 2," Center on PBIS, accessed on January 23, 2020, https://www.pbis.org/pbis/tier-2. 
encourage acceptable behaviors through positive reinforcement and remove stimuli that trigger and perpetuate problem behavior. This means that in PBIS, the teacher wants the child to act in a way that is best for them and for their classmates, and that the teacher sets the student up for success. Both PBIS and Nietzsche understand that humans generally have a will that works towards an end, and with this will comes agency. In managing people, this agency and will must be addressed in a humanistic manner, meaning that those in power respect the capacity of those who are subordinated to make choices and meet their own needs.

Humans have agency or the ability to act because it serves a purpose, their behavior is a means to an end. Punishing or stifling that action or will can only serve to benefit the person doing the punishing, as it asserts dominance in enacting pain. According to Nietzsche, "[The concept that] every will should regard every other will as its equal, this would be a principle hostile to life, an attempt to assassinate the future of man, a sign of fatigue and a secret path to nothingness." 11 This is Nietzsche's attempt to acknowledge that power is necessary to the function of society, while also acknowledging that when two wills come into conflict that punishing the one with less power is not the answer. The justice system does not work because it is punitive, it tries to enact revenge for the injured party and does not take into account the accused's will and agency. This issue is exacerbated by feelings resulting from ressentiment.

So, PBIS and Nietzsche both discourage the use of punishment, as it does not create conditions for any moral improvement in the subject being punished. The root of this idea is that the creditor (teacher) and debtor (student) power dynamic is unequal; the creditor can enact any kind of unnecessary harm onto the debtor because of this unequal dynamic. This in turn creates the feelings of ressentiment in the debtor; and perpetuates the harm created by the initial action of the debtor. Neither PBIS nor Nietzsche would argue for the removal of these power dynamics entirely, as power imbalances are necessary for organization and function of society. But both methodologies would call for the removal of revenge-seeking justice. The theoretical connection between Nietzsche's critique of the justice system and PBIS has been established, and in the establishment of this connection I see a parallel between this idea and Michel Foucault's theories about power, knowledge, and discipline in Discipline and Punish: The Birth of the Prison.

\section{Foucault}

On Power

Michel Foucault's Discipline and Punish: The Birth of the Prison provides a critical account of the historical change in the way that people have been controlled in various ways by those in power. He

11. Nietzsche, Genealogy of Morality, 50. 
is extremely critical of discipline as a tool for subjugation and control, and would largely disagree with the fundamental tenets of PBIS. That being said, his work provides a point of comparison and critique from which the argument for PBIS can be made stronger. A fundamental concept throughout his account is the idea that power relations are pervasive and contentious; contentious in that they can be changeable. According to Foucault, "One should decipher in it [power] a network of relations, constantly in tension, in activity, rather than a privilege that one might possess; one should take as its model a perpetual battle rather than a contract regulating a transaction or the conquest of a territory."12 For Foucault, power relations are dynamics between two people in which one person has influence over the other, and these relations are deeply rooted in the function of society. These power relations have the capacity to be highly flexible depending on the circumstances in which the subjects find themselves. Power is an activity, in that it must be consistently maintained in order for the person to stay powerful. This means that simply because one has power in a given moment does not mean that they will always have power if they do not work to sustain this power. It is an active mode of being in which the person in power must be "in perpetual battle" to keep their power alive. This idea is built upon when Foucault discusses the dynamic between power and knowledge.

\section{On Power and Knowledge}

Power relations shift over time, and in this shift, there is a knowledge created. This knowledge accounts for the way the power relation was in the past, its potential to change over time, and its current state. Insight can be gleaned from the state of power relations over time; it may become evident why a certain person holds power over another, how she has managed to keep (or lose) this power, and what she has done with her power. Foucault explains, "Power produces knowledge...power and knowledge directly imply one another; that there is no power relation without the correlative constitution of a field of knowledge, nor any knowledge that does not presuppose and constitute at the same time power relations." 13 When this knowledge is produced from the shift in power dynamics, it greatly affects how power relations are carried out in the future. If someone's power can be undermined, it will not be long before she no longer holds power. Those in power have largely dictated what kind of truth has been produced as a result of this relationship between power and knowledge. Truth is dictated by those in power because they have the means to determine the standards by which credibility is determined, or put differently, the categories of

12. Michel Foucault, Discipline and Punish: The Birth of the Prison, trans. Alan Sheridan, (New York: Vintage Books, 1977), 26.

13. Foucault, Discipline and Punish, 27. 
thought that define what is true. Foucault's description of power, knowledge, and the relationship between the two is in conversation with the foundational philosophies of PBIS.

\section{Power, Knowledge, and PBIS}

In PBIS, the student and the teacher are interlocked in a power relation. This is a necessary dynamic, in that students (especially young children) have abundant impulses that may not serve their best interests or be safe for those around them. A certain level of autonomy is surrendered to the teacher by the student, in order to avoid unwanted consequences. The key distinction between PBIS and traditional teaching models is that the teacher is required to know how exactly to get the student to surrender their autonomy in particular ways that are specific to each student. For example, Susie acts out in class because she seeks social validation through connection, so isolating her would not meet this need. The teacher knows this, so after saying to Susie "Susie, it seems like you need to talk to your friends, but now is not an appropriate time to talk to them. Would you like to have a conversation with me after or can you wait to talk to them after I am done instructing the class?" The main idea in saying this would be to use a kind but frank tone, making clear that this is not a form of punishment but a willingness to validate Susie's need for connection. Giving Susie the choice would make it feel like there is a transfer of some of the teacher's power to her.

This is a tool for the maintenance of power in that the teacher is always in control of providing options to the student. Providing the illusion of choice requires that the teacher has respect and values her students, that she cares about the well-being of her students, and that these dispositions are demonstrated in the teacher's tone and in her actions. The teacher must act (as much as she can) without bias or prejudice, seeing each unwanted behavior as a teaching moment. While these things take great skill and patience, for PBIS to work most effectively there must be a culture of care and respect created prior to the implementation of its methodologies. That being said, Foucault is critical of discipline as it is used within power relations, and exploring his criticism helps bring out what exactly PBIS does.

\section{On Punishment}

Discipline and Punish: The Birth of the Prison tracks the historical movement of how people have been and continue to be discouraged from criminal action, explaining how and why people were punished in certain ways at different moments in time. Foucault identifies the move from corporeal punishment to a "soul discipline" intended to permanently alter the way that a subject comports themselves. He explains that "the expiation that once rained down upon the body must be replaced by a punishment that acts in depth on the heart, the thoughts, the inclinations...Punishment ... 
should strike the soul rather than the body."14 Throughout this work he explains that people attribute this move from corporeal punishment to discipline as a form of humanistic growth; that humanity has become more compassionate as time goes on. He is highly skeptical of this idea and goes to great lengths to prove that it is simply untrue.

Foucault claims that Western society has (generally) moved away from corporeal punishment because it is ineffective as a means for control. 15 Harming the body of someone who committed a crime makes those in power the villain and the criminal the martyr. Subjects in society see those in power punish criminals in this way, and contrary to the goal of this type of punishment, become critical of those in power. These subjects identify with the criminal being punished, because both the subjects and the criminal are subordinated in the power relation between the government and its people. Seeing those in power inflict pain on the criminal serves to create empathy for the criminal and breaks down the power relation between people and their government.

\section{On Punishment and PBIS}

The relationship described above is comparable to PBIS in that the culture of care maintains the teacher/student power dynamic. Avoiding punishment is central to the framework of PBIS, and the relationship between the government and its subjects is paralleled by the relationship between the teacher and her students. For society or a classroom to function, those in power must be able to maintain control. Punishment is not an effective tool for the maintenance of control. This fact serves as the basis for the use of a teaching discipline in PBIS, of which Foucault is quite skeptical.

\section{On Discipline}

Going further, Foucault extrapolates the issues with this "soul discipline", and he begins to implicitly critique PBIS. Discipline is a necessary tool for control, but in its most cruel forms it can be used for a sinister manipulation of those who are subjugated. On this notion, Foucault writes, 'Discipline produces subjected and practised bodies, 'docile' bodies ... it dissociates power from the body; on the one hand, it turns it into an 'aptitude', a 'capacity', which it seeks to increase; on the other hand, it reverses the course of the energy, the power that might result from it, and turns it into a relation of strict subjection."16 The kind of discipline that Foucault explains here is one that seeks to render subjects into modes of productivity, erasing their capacities for spontaneity and creativity. Foucault's account offers a point of critique for PBIS as a tool for control, however this work attempts to provide a nuanced account of the necessity of such programs of discipline in institutions. This type of discipline says, "those without power must serve as a means to ends that

14. Foucault, Discipline and Punish, 16.

15. Foucault, Discipline and Punish, 48.

16. Foucault, Discipline and Punish, 138. 
are not their own, they must serve the ends of those in power." Those without power are shoved into cubicles, have their autonomy removed, and are made into cogs of a machine. The sustained function of this discipline machine takes great effort, making those who are subjugated all the more docile. It could be argued that the teaching discipline utilized in PBIS follows this model of "strict subjection" through discipline.

\section{On Discipline and PBIS}

However, the story is far more complex than that. It goes without saying that most teachers (hopefully) do not seek to turn their students into mere cogs. There is a level of routine and order that must be maintained in a classroom setting. When students are very young, teachers must inform their students as to why their subjugation is expected and necessary in each given moment. The teacher accomplishes this by setting clear expectations before any activity is carried out. This is crucial to the maintenance of mutual respect between student and teacher and therefore it is crucial to the maintenance of power. If people know why their subjugation is necessary, and if they feel respected in their subjugation, then they are less likely to resist necessary power dynamics. In addition, teachers should be attempting to help guide and form their students into well-educated citizens. Docility is required, but it is informed docility, or rather a compromise between the teacher and student towards a greater end (the student's education). Despite all of this, Foucault is relentless in his critique of discipline and there are added layers of nuance that must be attended to.

\section{On Examination}

Relating his critique directly to schooling, Foucault explores the issues with examination. Academic rank, the grading system, and standardized tests are some examples of the perpetuation of his issues with examination; these are ways that academic progress is measured and therefore the worth of a student's labor. He states, "The examination, surrounded by all its documentary techniques, makes each individual a 'case': a case which at one and the same time constitutes an object for a branch of knowledge and a hold for a branch of power." 17 To create a "case" is to have documentation that ranks, labels, or categorizes a certain person. It creates a branch of knowledge in that this information holds power over an individual by ascribing them a number, or a value. This number can be used against the student if it is low, or it can be used to uplift the student if it is high. Both are problematic in that they do not really provide any kind of constructive criticism. For what can be built with a number? Essentially, if each student's "case" is used against another to set a standard or norm, then it becomes harmful. It can be argued that PBIS creates a "case" for students' behavior.

17. Foucault, Discipline and Punish, 191. 


\section{On Examination and PBIS}

It is necessary to collect information on a student in order to understand why they are behaving a certain way. To address behavior, teachers must understand what motivates a child to act in a certain way. Understanding motivation requires a kind of psychological "case" for the child. While it can be said that the development of such a "case" is for the purpose of gaining power over the student, there is more to it. To serve individuals, those with power must know who they are serving, in order to best address the needs of those over whom they have power. Information collection is not inherently harmful when it is done by those in power. Although there is a problematic side to the development of a "case"; when teachers compare cases, when they use student information for class rank and when numbers determine the opportunities that students can access, then what Foucault is addressing holds water. Continuing with this work, Foucault connects his ideas about the modernization of disciplinary techniques to the panopticon, an architectural metaphor for power.

\section{On Panopticism}

The panoptic prison, or the "panopticon" is a theoretical architectural plan for a prison in which the inmates are never certain if they are being watched. In this way, it is a model for power in its most efficient form, because less people are required to survey those who are subjugated; less people have to enforce power. As Foucault states, "The major effect of the Panopticon: to induce in the inmate a state of conscious and permanent visibility that assures the automatic functioning of power ... the inmates should be caught up in a power situation of which they themselves are the bearers."18 In Foucault's view, this building makes it so no one knows if they will face consequences for any rebellious action, or if they are being watched at all. The idea within these two ambiguities that those who are subjugated will feel as though they should conform to the "norm." They will act in concert with their fellow subjugates, re-enacting the status quo, as they feel the weight of power subconsciously. In this way, their souls have become disciplined in that power structures have been ingrained into their every action. Those who are subjugated cannot confront those in power, or work to change power relations if they do not see the face of power- and in this way they are kept powerless. Power is maintained by the panopticon through the use of ambiguity, which begets conformity motivated by uncertainty. Conformity limits spontaneity and turns once fluid power relations into power structures that become inflexible. The panopticon functions as a model for our modern experience of power and discipline. This modern notion of power and discipline holds true

18. Foucault, Discipline and Punish, 201. 
in our institutions, such as, hospitals, prisons, schools, and our government. PBIS complicates Foucault's ideas into a more humanistic notion of modern discipline.

\section{On Panopticism and PBIS}

In a classroom setting, children should be aware that they are being monitored, but they should have the capability to determine how they act. This means they should still have choice over their actions, they should know what they are expected to do, but they should feel comfortable collaborating with others. People of any age need meaningful connections with others, play, and the ability to try something new. This would be a kind of intelligent education, if those in power respectfully guided human behavior, if everyone took the time to be a teacher, then a new form of discipline could be developed. PBIS serves as the foundation for the development of this new mode of discipline. The methods used in PBIS leave room for human spontaneity, while still maintaining order. John Dewey explains how the methods in PBIS function, and based on that function he begins to develop a practical understanding of how this new mode of discipline would work.

\section{Dewey}

\section{On Impulses}

John Dewey's understanding of impulses in the young is relevant to reforming educational methodology. In Human Nature and Conduct, he critiques how adults in the past have mistreated the docility of the young by trying to foster a sense of conformity before anything else. According to Dewey, "In the case of the young it is patent that impulses are highly flexible starting points for activities which are diversified according to the ways in which they are used."19 For Dewey, impulses in the young are the first step in activity, and they are highly flexible because they have the capacity to be redirected. This connects to PBIS because this understanding of the flexibility of impulses in the young is part of the reason that PBIS works. These impulses are the underlying reason for a certain pattern of behavior. PBIS works to redirect these impulses in an intelligent way that guides children to better action. Through positive reinforcement, children's impulses are directed towards safer or more manageable actions. Dewey's conception of impulses in the young connects to operant behavior because both are describing the underlying reason motivating a given action, and PBIS seeks to redirect this impulse. Through this process of redirection of impulses, better habits are formed.

\section{On Habits}

Better habits are those actions that both serve the needs of the actor and are appropriate for

19. John Dewey, Human Nature and Conduct: An Introduction to Social Psychology, ed. Jo Ann Boydston, (Carbondale: Southern Illinois University Press, 1988), 69. 
the environment. Habits are patterns of behavior that are unconsciously set by the influences in an individual's environment, and they create the perspective through which a subject understands the world. While habits are greatly influenced by the environment in which a subject exists, they are primarily a response to unmet needs. Habits are significant because "the moral problem in child and adult alike as regards impulse and instinct is to utilize them for the formation of new habits ... or the modification of an old habit so that it may adequately be serviceable under novel conditions." 20 So, for Dewey, our habits form us as subjects, and they determine how adaptable we are in new situations. Our impulses direct this adaptability by driving habits into conflict with other habits, impulses, or factors in the environment. This connects to PBIS, because in trying to redirect impulses, PBIS is trying to create new habits. Impulses are redirected through positive reinforcement of good behavior and redirection of non-preferred behaviors.

For example, say a child has an impulse to get attention from adults through acting out. The teacher knows this child's impulse, so when the child is throwing sand the teacher can address the impulse of attention seeking through negative means by offering the child one on one time with an adult in a non-punitive way. In addition, the teacher can tell the child that next time they can get attention by simply asking for it. This process is repeated until (ideally) a new habit is formed based on the teacher's response to the child's action. Next time, instead of acting out to get attention, the child will have hopefully developed the habit of asking for attention through verbal communication instead of acting out. Dewey's conceptions of impulses and habits connects to operant behavior, and therefore PBIS uses Dewey's ideas by redirecting impulses to create habits.

\section{On Customs}

The process of habit-creation is embedded into the social world when enough people become habituated in a certain way, then customs are created. This has implications for children, because customs set a standard of "good" behavior to which they are expected to conform, even though they may not know or understand these adult customs yet. According to Dewey, "The weight of adult customs has been upon retaining and strengthening tendencies towards conformity, and against those which make for variation and independence."21 Dewey explains later that if adults "strengthen tendencies towards conformity" in children, this will lead to the stagnation of customs over time. This stagnation of customs is a problem because, if we don't teach children how to be independent thinkers, then nothing will improve. This relates to PBIS because the goal of PBIS is to teach children how to direct their impulses towards better actions (thereby developing intelligent

20. Dewey, Human Nature and Conduct, 75.

21. Dewey, Human Nature and Conduct, 70. 
habits). Through the development of intelligent habits by a large group, better customs can be created. The creation of intelligent habits and eventually the creation of intelligent customs connects to the goal of PBIS, which is long-term change in behavior in a subject's life. Customs are the habits of a social group, so if the impulses of children are redirected into better habits, then over time the social group will form better customs. Therefore, PBIS can be seen as the practical application of Dewey's ideas about impulses, habits, and customs.

PBIS and Dewey's ideas serve to create better customs through the intelligent education of young children, but what are better customs for? Better customs, just like better habits, are modes of behavior that move with the environment. In Dewey's words, "When customs are flexible and youth is educated as youth and not as premature adulthood, no nation grows old."22 If grownups treat children as if they were tiny adults; expecting them not to do anything that is contrary to customs, develop habits, and express impulses towards only proper acts, everyone will ultimately be disappointed. PBIS and Dewey both recognize that children's needs are valid and, thus, need to be validated. Children's needs must be directed by adults only because they have not had the life experience to manage them. Being authoritative and punishing children is ineffective because punishment does not address the underlying impulse that pushes a child to act. If we teach children intelligently, understanding them as complex humans that need to have their impulses redirected towards preferred action; our customs will eventually adapt. Put differently, customs will adapt through the formation of intelligent habits originated from the proper re-direction of impulses in the young. Through Dewey's work, PBIS can be understood as a tool to redirect impulses, create better habits, and eventually form better customs.

Impulses, Habits, Customs, and PBIS

PBIS seeks to direct impulses and form better habits, but what can be done about existing social norms and customs that challenge preferred behaviors? For Dewey, customs are socially adopted habits or norms that dictate what is acceptable or repugnant. Essentially, they are the unseen rules of social behavior. Customs are significant in education because adults unthinkingly pass on these customs to children that don't quite understand how to follow them yet. Dewey explains this relation: "Our usual measure for the 'goodness' of children is the amount of trouble they make for grownups, which means of course the amount they deviate from adult habits and expectations." 23 Here, adult habits and expectations can be extended to mean customs as well. While PBIS still tries to promote "goodness" in children, there is no fixed "good" child in PBIS. PBIS

22. Dewey, Human Nature and Conduct, 73.

23. Dewey, Human Nature and Conduct, 73. 
strives to attain an understanding of a given child's impulses and habits in order to best address their needs. For example, two children could be throwing blocks, a caregiver using PBIS methods would know that one child is throwing blocks to gain attention from a caregiver and the other is doing it out of social frustration. To address the attention seeking behavior, the caregiver would give the child attention and explain how the child could get their needs met by asking. To address the child experiencing social frustration, the caregiver would try to redirect the child into a "calm down area" in which the child can settle down before returning to their peers. So, both Dewey and PBIS recognize that we cannot frame children in a way that makes them have to strive towards a kind of "good" shaped by custom. Children are people and people are far more complex than that. PBIS and Dewey both seek to avoid the mindless passing of customs from generation to generation.

\section{The Goal of PBIS and Dewey; an Intelligent Education}

When Dewey explains how to create intelligent customs, the connection between his ideas and PBIS is made even stronger. Dewey and PBIS have a similar goal for children through the redirection of impulses and the formation habits- to create subjects that are better prepared for the indeterminate nature of life. Dewey states, "A truly humane education consists in an intelligent direction of native activities in the light of the possibilities and necessities of the social situation. But for the most part, adults give training rather than education." 24 PBIS strives to "[intelligently direct] native activities in the light of the possibilities of the social situation" by trying to understand each child's needs and address them accordingly. In addressing a child's needs (or impulses), the caregiver is attempting to direct the child towards a preferred behavior, thereby creating a better habit. The goal of PBIS is to redirect children's impulses through positive affirmation, which is supposed to curb non-preferred behaviors. These non-preferred behaviors arise for a reason; the child's impulse to behave a certain way. By addressing this impulse to behave in a non-preferred manner, the child should no longer feel the need to behave that way. In addition, the positive reinforcement provides another reason for the child to act in a preferred manner. This description of PBIS as a behavior management system serves to explain how the ideas behind the system are an outgrowth of Dewey's notions of human behavior. PBIS does not just train children by authoritatively punishing them if they do not conform to adult customs. In the "intelligent direction of native impulses" caregivers that use PBIS create better habits and ultimately create better customs in and through the education of children. Thus, In educating children, PBIS and Dewey share the same goal.

A counter argument for the connection between PBIS and Dewey could be that if caregivers

24. Dewey, Human Nature and Conduct, 70. 
are not aware of the prevailing customs, then they will still pass them down to children. If a caregiver is unaware that they are perpetuating a social norm by directing a child towards their personal preferred action, then old customs may prevail. For example, a well-meaning caregiver could encourage a little boy to stop playing with a doll and play with cars instead. While this seems innocent enough, this is subtly reinforcing gender norms, because dolls are stereotypically seen as a toy for girls and cars for boys. The caregiver is technically using PBIS and re-directing the little boy's impulse to play with a toy and presenting him with a viable alternative to that behavior. Using PBIS this way, the caregiver would be upholding a social norm that runs counter to the direction towards which society is moving, encouraging conformity and contradicting Dewey's ideas about customs.

For PBIS to work, caregivers must use a child-centered notion of PBIS, meaning the child is only redirected when necessary. It is necessary to redirect a child when their well-being, the safety of others, or the movement of the classroom is going to be compromised if the child's action goes unimpeded. So, there is still a strong connection between PBIS and Dewey's ideas about impulses, habits, and customs. This connection is just dependent on the good sense of caregivers to know when to use PBIS and why. PBIS is a practical application of Dewey's ideas about the education of children through the redirection of their impulses, the formation of their habits, and the eventual creation of better customs.

The common ideas that are central to PBIS and Dewey's work are: impulses must be recognized in order to form habits, and there are intelligent ways to direct impulses to form better habits. In Dewey's work, the connection between methodologies employed by PBIS is taken a step further in the prediction of better customs as a result of the formation of intelligent habits. Both frameworks call for education over punishment, and they seek to alter the course of behavior longterm. Being informed by Dewey's ideas helps create a renewed sense of purpose in the social function of PBIS. The purpose of this linkage is to emphasize that we teach children by guiding them because we want them to eventually guide others. We treat them with respect because we want them to be respectful, and we maintain and hold power only when necessary. Power is maintained through redirection of impulses, clear communication of options, and effective, calm reasoning. This power is intended to move towards a kinder form of discipline that allows for the spontaneous and informed movement of will, agency and autonomy.

\section{Conclusion}

Leaving this room for spontaneity allows for subjects to take responsibility for their action that I would argue resembles morality. Morality in this context would mean an action that is guided by a set of principles aiming at a common good - the idea that we are all part of a larger human 
project. Theoretically, discipline should look like constant supervision for the sake of a common good. People know that it is necessary for them to be subjugated in specific ways and are respected in their necessary subjugation. Subjects act within a set of clear guidelines because the face of power is right in front of them, respectfully guiding their action. Knowledge is shared and power dynamics are made transparent, empowering those who are subjugated to accrue power if they so choose.

Nietzsche's On the Genealogy of Morality, explains that the unequal power dynamics between creditor (teacher) and debtor (student) create space for abuses of power by inflicting justice onto the debtor; further discouraging the use of punishment in the justice system. Similarly, both argue that at the societal level punishment does not allow for a reformed subject to be produced; it simply forms an unproductive resentment. Building on these ideas, Foucault provides a historiography of the shift from old notions of corporeal punishment to a modern notion of power, discipline, and knowledge, which I connect to a new mode of discipline inspired by PBIS. Finally, in Human Nature and Conduct, Dewey established a connection between the formation of habits through impulses and eventually customs and the foundational ideas of operant behavior and redirection in PBIS. Both theoretical methodologies derive the conclusion that education is the best way to alter behavior for the better by validating the agency of those who are subjugated, and both acknowledge that punishment is not the way to achieve this goal.

Moving forward, theories of discipline and punishment at the societal level should resemble the practices laid out by PBIS, Dewey, Nietzsche, and Foucault. Speaking to human inclination, I believe that these works have accurate contributions to the theoretical or philosophical values in any institution that deals with serving populations. These ideas can be implemented in schools, prisons, nursing homes, the justice system at large and many other forms of micro-societies. Theory can only do so much, but it is my hope that these ideas will act as the first step in initiating a philosophical shift in the way that people are managed. This discussion of this first step serves to inspire a new kind of discipline, to be researched in the near future. 